\title{
Madame de Maintenon. Une femme de Lettres?, sous la direction de Ch. Mongenot et M. E. Plagnol-Diéval
}

\section{Monica Pavesio}

\section{(2) OpenEdition}

1 Journals

\section{Edizione digitale}

URL: http://journals.openedition.org/studifrancesi/2138

DOI: 10.4000/studifrancesi.2138

ISSN: 2421-5856

\section{Editore}

Rosenberg \& Sellier

\section{Edizione cartacea}

Data di pubblicazione: 1 aprile 2014

Paginazione: 140

ISSN: 0039-2944

\section{Notizia bibliografica digitale}

Monica Pavesio, «Madame de Maintenon. Une femme de Lettres?, sous la direction de Ch. Mongenot et M. E. Plagnol-Diéval », Studi Francesi [Online], 172 (LVIII | I) | 2014, online dal 01 avril 2014, consultato il 18 septembre 2020. URL : http://journals.openedition.org/studifrancesi/2138; DOI : https://doi.org/ 10.4000/studifrancesi.2138

Questo documento è stato generato automaticamente il 18 settembre 2020.

\section{(c) (1)}

Studi Francesi è distribuita con Licenza Creative Commons Attribuzione - Non commerciale - Non opere derivate 4.0 Internazionale. 


\title{
Madame de Maintenon. Une femme de Lettres?, sous la direction de Ch. Mongenot et M. E. Plagnol-Diéval
}

\author{
Monica Pavesio
}

\section{NOTIZIA}

Madame de Maintenon. Une femme de Lettres?, sous la direction de Ch. MONGENOT et M. E. PLAGNOL-DIÉVAL, Presses Universitaires de Rennes, 2012, pp. 322.

1 Fin dal XVII secolo, la sposa morganatica di Luigi XIV è stata accusata di freddezza, intolleranza, instabilità. Attorno alla figura di Madame de Maintenon si è creato un mito negativo, che ha condizionato la ricezione e lo studio delle sue opere, nei secoli successivi. Le è rinfacciata un'influenza negativa sul sovrano nelle questioni politiche e religiose e la si ritiene colpevole del decadimento della vita culturale alla fine del regno di Luigi XIV. Solo successivamente, si è assistito ad una riabilitazione della Marchesa, grazie alla sua opera importante di educatrice nel collegio di Saint-Cyr, ma poca attenzione è stata dedicata alla sua opera letteraria.

Chi era effettivamente Madame de Maintenon? I saggi, inseriti in questo volume, cercano di rispondere all'interrogativo, partendo dall'analisi della sua corrispondenza e dei suoi scritti pedagogici. Si esplora la dimensione retorica ed estetica dei suoi testi, troppo a lungo ritenuti spontanei, frutto, invece, di un'accurata padronanza di precise strategie discorsive. Si passa poi a riflettere sulla ricezione e sull'influenza degli scritti di Madame de Maintenon nella storia letteraria francese ed europea.

3 Il volume, che riunisce storici e letterati francesi e stranieri, offre una panoramica interessante sugli scritti poco conosciuti e troppo a lungo dimenticati, di una grande protagonista del Grand Siècle. 